
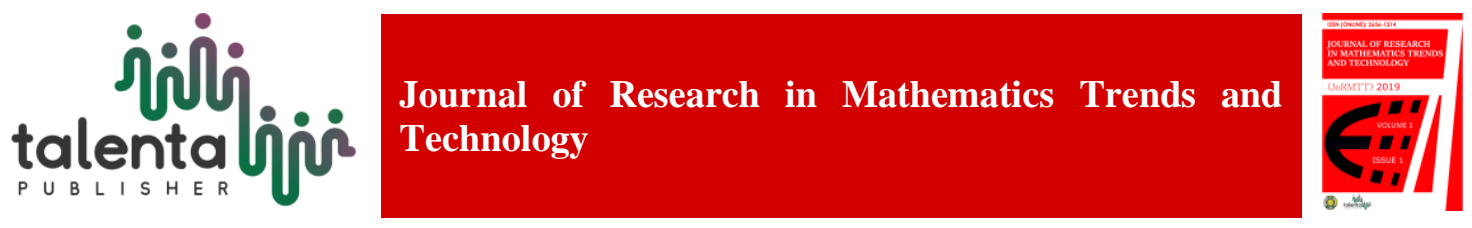

\title{
An Analytical Solution of 1-D Pseudo Homogenenous Model for Oxidation Reaction Using Homotopy Perturbation Method
}

\author{
Aang Nuryaman \\ Department of Mathematics, Lampung University, Lampung, Indonesia
}

\begin{abstract}
In this paper, we propose an analytical solution of convective-diffusion equation that derived from an oxidation reaction in a chemical reactor. Here, concentration of feed gas as dependent variable. In this study, the reaction are assumed to be a one-dimensional pseudo homogeneous model and it is evaluated at a certain reaction rate. By rescaling process, the nonlinear term of the reaction rate can be approximated by a linear term, resulting a linear convective-diffusion equation with an initial condition and a set of boundary conditions. Here, we present an analytic solution of the initial condition and the boundary conditions using the homotopy perturbation method. The results show that at the end of the reactor, the solution is in agreement with numerical solution of the initial and boundary conditions.
\end{abstract}

Keywords: Convective-diffusion Equation, 1-D Pseudo Homogeneous Model, Homotopy Perturbation Method

Abstrak. Dalam makalah ini, kami mengusulkan solusi analitik persamaan konveksi-difusi yang diturunkan dari reaksi oksidasi dalam reaktor kimia. Di sini, konsentrasi gas umpan sebagai variabel dependen. Dalam penelitian ini, reaksi diasumsikan sebagai model homogen semu satu dimensi dan dievaluasi pada laju reaksi tertentu. Dengan proses rescaling, istilah nonlinier dari laju reaksi dapat didekati dengan istilah linier, menghasilkan persamaan konveksi-difusi linier dengan kondisi awal dan serangkaian kondisi batas. Di sini, kami menyajikan solusi analitik dari kondisi awal dan kondisi batas menggunakan metode perturbasi homotopy. Hasil penelitian menunjukkan bahwa pada akhir reaktor, solusinya sesuai dengan solusi numerik kondisi awal dan batas.

Kata Kunci: Persamaan Konveksi-difusi, Model Homogen Semu 1-D, Metode Perturbasi Homotopy

Received 14 November 2018 | Revised 20 January 2019| Accepted 27 February 2019

\section{Introduction}

Oxidation is a chemical reaction that take places between a substrate of reactant with oxygen. For hydrocarbon oxidation, if the reaction is complete, it will produce carbon dioxide $\left(\mathrm{CO}_{2}\right)$ gas and water $\left(\mathrm{H}_{2} \mathrm{O}\right)$ molecules. In a catalytic reactor, oxidation can be considered as a fluid dynamic problem in porous medium where the feed gas and catalist respectively as fluid and porous medium.

\footnotetext{
*Corresponding author at: Lampung University, Lampung, Indonesia

E-mail address: aang.nuryaman@fmipa.unila.ac.id
} 
Dynamic of dependent variables in the oxidation process at every time and position can be described in a convective-diffusion equation system with nonlinear reaction rate terms. Several mathematical models have been discussed to describe the dynamics of dependent variables, especially concentration and temperature. The main difference between the models depends on the heat dissipation. Here, the heat dissipation refers to axial heat conductivity, inter-phase heat transfer or heat transfer in catalyst granules and heat radial diffusion. The contribution of heat dissipation factor will give a different model. In general, the mathematical models that used are the pseudo homogeneous models and heterogeneous models [1].

The existence of non-linear terms in the mathematical model of oxidation reactions makes numerical approach as an alternative to describe the behavior of the dynamics of dependent variables. But there are some researchers who carried out analytical approaches, using certain assumptions, to discuss the behavior of dependent variables. In [2], Nuryaman et al. presented a singular perturbation problem for conversion variable in steady state conditions and solved using matched asymptotic methods. Furthermore, Nuryaman and Gunawan (see [3]) used the asymptotic expansion method to solve singular perturbation problems for temperature and concentration variables in steady state conditions. In those study, the authors used onedimensional (1-D) pseudo homogeneous model.

In this article, we will discuss the unsteady state solution of conversion of the oxidation reaction in a catalytic chemical reactor through a different analytical approach. We assume that the model are one-dimensional pseudo homogeneous and the reaction rate takes place at a fixed temperature. Rescalling the variables, we obtain a dimensionless linear convective-diffusion equation. We solve the derived equation using the homotopy perturbation method.

\section{Materials and Methods}

Here, we use 1-D pseudo homogeneous model that adopted from [4], those are

$$
\begin{aligned}
& K \frac{\partial T}{\partial \tau}=\lambda_{a x} \frac{\partial^{2} T}{\partial z^{2}}-u\left(\rho c_{p}\right)_{s} \frac{\partial T}{\partial z}+(-\Delta H) g(T) C-U_{w} a_{w}\left(T-T_{c}\right) \\
& \epsilon \frac{\partial C}{\partial \tau}=\epsilon D \frac{\partial^{2} C}{\partial z^{2}}-u \frac{\partial C}{\partial z}-g(T) C
\end{aligned}
$$

with $K=(1-\epsilon)\left(\rho c_{p}\right)_{s}+\epsilon\left(\rho c_{p}\right)_{g}, g(T)=\frac{\eta k_{\infty} k_{c} a_{v} \exp \left(-E_{a} / R T\right)}{k_{c} a_{v}+\eta k_{\infty} \exp \left(-E_{a} / R T\right)}$ and boundary conditions

$$
\begin{array}{ll}
-\frac{\lambda_{a x}}{u\left(\rho c_{p}\right)_{g}} \frac{\partial T}{\partial z}=T_{i n}-T,-\frac{\epsilon D}{u} \frac{\partial C}{\partial z}=C_{i n}-C, & \text { at } z=0 \\
\frac{\partial T}{\partial z}=0, \frac{\partial C}{\partial z}=0 & \text { at } z=L
\end{array}
$$

The variable of $T=T(z, \tau)$ and $C=C(z, \tau)$, respectively, denote temperature (Kelvin, $\mathrm{K}$ ) and consentration (molar) of feed gas at position $z$ and time $\tau$. Equations (1)-(2) are called Danckwert boundary conditions [5] where $T_{\text {in }}$ and $C_{\text {in }}$ denote temperature and concentration of feed gas that enter the reactor, and $\mathrm{L}$ denotes the length of reactor $(\mathrm{m})$. Here, the initial conditions assumed $T(z, 0)=T_{0}=T_{i n}$, and $C(z, 0)=0$

Non dimensionalization process gives dimensionless equations as follow [6]

$$
\begin{aligned}
& \theta_{t}=k_{1} \theta_{x x}-k_{2} \theta_{x}+k_{3} g(\theta)(1-\chi)-k_{4}\left(\theta-\theta_{c}\right) \\
& \chi_{t}=k_{5} \chi_{x x}-k_{6} \chi_{x}+k_{7} g(\theta)(1-\chi)
\end{aligned}
$$

with boundary conditions

$$
\begin{aligned}
& k_{1} \theta_{x}(0, t)=k_{2}(\theta(0, t)-1), \quad k_{5} \chi_{x}(0, t)=k_{6} \chi(0, \tau), \\
& \theta_{x}(1, t)=0, \quad \chi_{x}(1, t)=0
\end{aligned}
$$


In previous research, Nuryaman et al. (see [2]) constructed a singular perturbation problem using Equations (5)-(8) at steady state and takes place with a certain reaction rate in which the whole process of the reactor still workable and with small temperature variation and no heat loss. This leads to an equation in terms of the conversion variable only. An asymptotic solution using matched asymptotic method obtained until two terms.

In this paper, we study dynamic of the conversion variable using Equation (5)-(8) at unsteady state and takes place with a certain reaction rate where the reaction spontaneously. This leads to an equation in terms of the conversion variable only as follow

$$
\chi_{t}=k_{5} \chi_{x x}-k_{6} \chi_{x}+\bar{k}_{7}(1-\chi)
$$

with boundary conditions and intial condition

$$
k_{5} \chi_{x}(0, t)=k_{6} \chi(0, t), \quad \chi_{x}(1, t)=0, \quad \chi(x, 0)=0 .
$$

In next section will be presented an analytical solution of the initial and boundary conditions (9)-(10) using homotopy perturbation method. This method was introduced in [7] where its basic idea is by introducing a homotopy parameter, namely $p$, with $p \in[0,1]$. Application of this method for partial differential method presented in [8] like below.

Consider the following differential equation

$$
L(u)+N(u)=f(r), \quad r \in \Omega
$$

with boundary condition

$$
B\left(u, \frac{\partial u}{\partial n}\right)=0, \quad r \in \Gamma
$$

where $L$ a linear operator, $N$ nonlinear operator, $B$ boundary operator, $\Gamma$ is the boundary of the domain $\Omega$, and $u$ is a known analytical function. Construct a homotopy $v(r, p): \Omega \times[0,1] \rightarrow \mathbb{R}$ which satisfies

$$
H(v, p)=(1-p)\left[L(v)-L\left(u_{0}\right)\right]+p[L(v)+N(v)-f(r)]
$$

Here $v \in \Omega, p \in[0,1]$ and $u_{0}$ is an approximation of initial solution Equation (11) which satisfies the boundary conditions (12). By (13), it follows that

$$
\begin{aligned}
& H(v, 1)=L(v)+N(v)-f(r) \\
& H(v, 0)=L(v)-L\left(u_{0}\right)
\end{aligned}
$$

If $p$ changes from 0 to 1 , then $v(r, p)$ changes from $u_{0}(r)$ to $u(r)$. In topology, this is called deformation, $L(v)-L\left(u_{0}\right)$ and $L(v)+N(v)-f(r)$ are called homotopic. Assume that the solution of (14) and (15) can be written as power series of $p$,

$$
v=v_{0}+p v_{1}+p^{2} v_{2}+\cdots
$$

with $v=v(x, t)$. Then the approximation of solution Equation (11) can be obtained as follow $u=\lim _{p \rightarrow 1} v=v_{0}+v_{1}+v_{2}+\cdots$.

\section{Results and Discussion}

Based on the procedure that explained in the previous section, to solve the problem in (9)-(10), we obtain, respectively, the linear and non linear operator as follow

$$
\begin{aligned}
& L(v)=v_{t} \\
& N(v)=-k_{5} v_{x x}+k_{6} v_{x}-\bar{k}_{7}(1-v) .
\end{aligned}
$$

From Equation (13) we get

$$
H(v, p)=v_{t}-u_{0 t}+p u_{0 t}+p\left[-k_{5} v_{x x}+k_{6} v_{x}-\bar{k}_{7}(1-v)\right]=0
$$


Based on the assumption that $v$ can be written in power series (16) then we obtain

$$
\begin{aligned}
& H(v, p)=\left(v_{0 t}+p v_{1 t}+p^{2} v_{2 t}+\cdots\right)-u_{0 t}+p u_{0 t} \\
& \quad-k_{5} p\left(v_{0 x x}+p v_{1 x x}+p^{2} v_{2 x x}+\cdots\right)+k_{6} p\left(v_{0 x}+p v_{1 x}+p^{2} v_{2 x}+\cdots\right)- \\
& \quad k_{7} p\left[1-\left(v_{0}+p v_{1}+p^{2} v_{2}+\cdots\right)\right]=0 .
\end{aligned}
$$

For initial solution, choose $u_{0}=0$.

Solution of (21) is obtained by solving the equation of the left and right side which have the same order $p$, i.e

$$
\begin{aligned}
& \text { Order } p^{0}: v_{0 t}-u_{0 t}=0 \\
& \text { Order } p^{1}: v_{1 t}+u_{0 t}-k_{5} v_{0 x x}+k_{6} v_{0 x}-k_{7}\left(1-v_{0}\right)=0 \\
& \text { Order } p^{2}: v_{2 t}-k_{5} v_{1 x x}+k_{6} v_{1 x}-k_{7}\left(-v_{1}\right)=0 \\
& \text { Order } p^{3}: v_{3 t}-k_{5} v_{2 x x}+k_{6} v_{2 x}-k_{7}\left(-v_{2}\right)=0 \\
& \vdots
\end{aligned}
$$

Initial conditions for every order- $p$ is

$$
\text { Order } p^{i}: v_{i}(x, 0)=0, i=0,1,2,3, \ldots
$$

By integrating respect to $t$, the general solution of (22) is

$$
v_{0}(x, t)=u_{0}(x, t)+c_{0}(x)
$$

Initial condition (26) and initial solution $u_{0}$ give $c_{0}(x)=0$. Thus the solution of Equation (22) is

$$
v_{0}(x, t)=0
$$

Next, for order $p^{1}$, by using Equation (28) and initial solution $u_{0}$ then Equation (23) becomes

$$
v_{1 t}=k_{7}
$$

with general solution is

$$
v_{1}(x, t)=k_{7} t+c_{1}(x) \text {. }
$$

Initial condition (26) gives $c_{1}(x)=0$, thus

$$
v_{1}(x, t)=k_{7} t .
$$

As for order $p^{2}$, by using (31) then Equation (24) becomes

$$
v_{2 t}=-k_{7}^{2} t
$$

with general solution is

$$
v_{2}(x, t)=-\frac{1}{2} k_{7}^{2} t^{2}+c_{3}(x) .
$$

Initial condition gives $c_{2}(x)=0$ so that

$$
v_{2}(x, t)=-\frac{1}{2} k_{7}^{2} t^{2} .
$$

By using the result of previous order, then the solutions for order $p^{3}, p^{4}, \ldots$ are:

$$
\begin{aligned}
& v_{3}(x, t)=\frac{1}{6} k_{7}^{3} t^{3} . \\
& v_{4}(x, t)=-\frac{1}{24} k_{7}^{4} t^{4} . \\
& \vdots \\
& v_{n}(x, t)=\frac{(-1)^{n+1}}{n !}\left(k_{7} t\right)^{n} .
\end{aligned}
$$

Therefore the solution of $\chi$ is

$$
\begin{aligned}
\chi(x, t) & =\lim _{p \rightarrow 1} v=v_{0}+v_{1}+v_{2}+\cdots \\
& =\lim _{p \rightarrow 1} p k_{7} t-\frac{1}{2} p^{2} k_{7}^{2} t^{2}+\frac{1}{6} p^{3} k_{7}^{3} t^{3}-\frac{1}{24} p^{4} k_{7}^{4} t^{4}+\cdots \\
& =k_{7} t-\frac{1}{2 !} k_{7}^{2} t^{2}+\frac{1}{3 !} k_{7}^{3} t^{3}-\frac{1}{4 !} k_{7}^{4} t^{4}+\cdots \\
& =1-e^{-k_{7} t}
\end{aligned}
$$


For comparison, here the analytical solution in Equation (38) will be compared with a numerical solution of Equation (10). We use finite difference method, by means forward time center space [9]. Plot of time $t$ versus conversion $\chi$ for some parameter values at certain position (the right end reactor) are shown in Figure 1 and Figure 2.

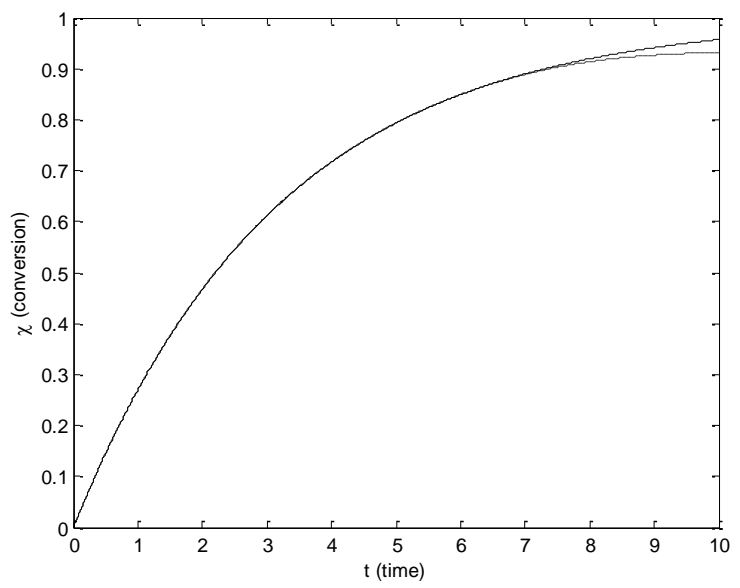

Figure 1 Plot $t$ vs $\chi$ for $k_{5}=0.001, k_{6}=0.1112$ and $k_{7}=0.315$ where solid line represents the analytical solution and dashed line represents the numerical solution

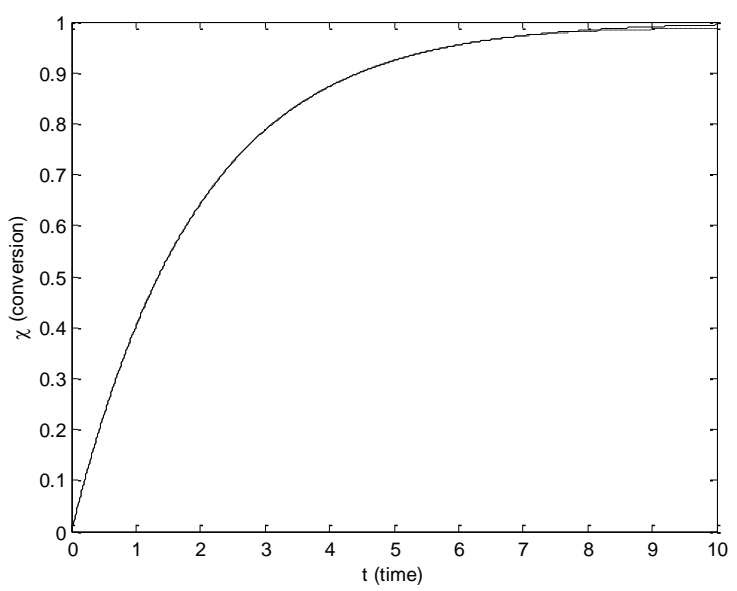

Figure 2 Plot $t$ vs $\chi$ for $k_{5}=0.001, k_{6}=0.1112$ and $k_{7}=0.515$ where solid line represents the analytical solution and dashed line represents the numerical solution.

\section{Conclusion}

Based on available data, we have studied a mathematical model for conversion variable of oxidation reaction in a chemical reactor at unsteady state condition. By using homotopy perturbation method we get an analytical solution approximation and compare it with a numerical solution. The results show that the analytical solution at the end of the reactor is in agreement with numerical solution of the initial and boundary conditions for parameter values that correspond to reaction rate are big enough.

\section{Acknowledgements}

The author would like to thanks the Dean of Faculty of Mathematics and Natural Sciences of Lampung University who have supported for my paper publication. 
[1] Y. S. Matros and G. A. Bunimovich, "Reverse-flow operation in fixed bed catalytic reactors", Catalysis Reviews: Science and Engineering, vol. 38, pp. 1-66, 1996.

[2] A. Nuryaman, A. Y. Gunawan, K. A. Sidarto and Y. W. Budhi, "A Singular Perturbation Problem for Steady State Conversion of Methane Oxidation Process in Reverse Flow Reactor”, ITB Journal of Science, vol. 44A, no. 3, pp. 277-287, 2012.

[3] A. Nuryaman and A. Y. Gunawan, "A Singular Perturbation Problem in Steady State of Methane Combustion Using Reverse Flow Reactor", Far East Journal of Mathematical Sciences (FJMS), vol. 102, no. 9, pp. 2069-2079, 2017.

[4] J. Khinast, Y. O. Jeong and D. Luss, "Dependence of Cooled Reverse-Flow Reactor Dynamics on Reactor Model”, AIChE Journal, vol. 45, no. 2, pp. 299-309, 1999.

[5] P. V. Dankwerts, "Continous Flow System: Distribution of Residence Times", Chem. Eng. Sci., 2: pp. 1-13, 1953.

[6] T. L. V. Noorden, S. M. V. L. Verduyn and A. Bliek, "The Efficient Computation of Periodic States of Cyclically Operated Chemical Processes", IMA Journal of Applied Mathematics, 68, pp. 149-166, 2003.

[7] J. H. He, "Homotopy Perturbation Technique", Comput. Math. Appl. Mech. Eng, vol.178, no. 3-4, pp. 257-262, 1999.

[8] L. Jin, "Homotopy Perturbation Method For Solving Partial Differential Equations With Variable Coefficient", Int. J. Contemp. Math. Sciences, vol. 3, no. 28, pp. 1395-1407, 2008.

[9] J. W. Thomas, Numerical Partial Differential Equations: Finite Difference Method, Springer, New York, USA, 1995. 